\title{
IDENTIFICAÇÃO DAS ORGANIZAÇÕES DA SOCIEDADE CIVIL (OSC) COM OS OBJETIVOS DE DESENVOLVIMENTO SUSTENTÃVEL: UM ESTUDO A PARTIR DO MAPA DAS OSC
}

\section{Camila Escudero}

\section{// resumo}

Os desafios para a implementação e consolidação da Agenda 2030, das Organizações das Nações Unidas (ONU), se aplicam, em maior ou menor grau, a todos os setores da sociedade. Simultaneamente, verifica-se um diálogo e convergência das finalidades de atuação do terceiro setor com as metas contempladas nos 17 Objetivos de Desenvolvimento Sustentável (ODS), o que coloca as organizações da sociedade civil (OSC) na função de ator social relevante - e, por que não, protagonista - nas relações nacionais, globais e multilaterais voltadas para a promoção dos ODS. O presente artigo teve como objetivo verificar de que maneira as OSC têm identificado suas ações e atividades práticas aos ODS, de acordo com o preenchimento desses dados no Mapa das OSC (IPEA, 2020). Entre os principais resultados, destaca-se que os dados sistematizados permitem uma melhor compreensão e oferecem uma perspectiva organizadora dos elementos que caracterizam as interações entre OSC e ODS.

palavras-chave: agenda 2030 | ODS | OSC | mapa das OSC. 


\section{OS ARTIGOS GIFE}

A série Artigos GIFE publica reflexões e análises de pesquisadores brasileiros de diferentes áreas do saber com o objetivo de estimular, ampliar e disseminar a produção de conhecimento qualificado sobre o campo da filantropia, do investimento social privado e da sociedade civil no Brasil.

A partir da premissa de que a produção de conhecimento sobre esses temas tem um papel fundamental na expansão, diversificação e qualificação da ação pública pela sociedade, a iniciativa também pretende contribuir para ampliar as conexões entre o setor, as universidades e os centros de pesquisa, promovendo e apoiando o envolvimento de novos atores com a temática e a circulação ampliada de ideias em torno dela.

Este texto integra a quarta edição dos Artigos GIFE, que propõe a publicação mensal de artigos selecionados por meio de chamada pública e convite a autores especialistas em temáticas específicas e relevantes para o setor, buscando apoiar e fomentar a produção de conhecimento sobre o investimento social no Brasil.

O Grupo de Institutos Fundações e Empresas (GIFE) é uma organização sem fins lucrativos que reúne associados de origem empresarial, familiar ou independente que investem em projetos de interesse público. Criado em 1989 como grupo de troca e colaboração e institucionalizado em 1995 por 25 organizações, tornou-se referência no campo da filantropia e do investimento social privado no Brasil.

Nesses mais de 20 anos de atuação, tem contribuído para o fortalecimento de práticas e ações a serviço do bem comum no país, trabalhando para expandir, qualificar e fortalecer o investimento social privado, diversificar e ampliar atores e recursos, criar referências e estimular boas práticas de gestão, bem como articulando o setor com a sociedade e a agenda pública. Atualmente, o GIFE reúne mais de 160 associados que, somados, aportam mais de 3 bilhões de reais por ano em projetos próprios e no apoio a projetos de terceiros. 


\section{artigos \\ GIFE}

\section{INTRODUÇÃO}

Os Objetivos de Desenvolvimento Sustentável (ODS) fazem parte da Agenda 2030 estabelecida por 193 líderes mundiais durante a Cúpula das Nações Unidas (ONU), realizada em setembro de 2015, em Nova York (EUA). Trata-se de um ambicioso plano de ação universal, ou seja, que se aplica a todos os países do mundo - construído a partir dos resultados da Rio $+20^{1}$ e que leva em conta o legado dos Objetivos de Desenvolvimento do Milênio $(\mathrm{ODM})^{2}$. Estabelece 17 pontos integrados e indivisíveis, mesclando as três dimensões do desenvolvimento sustentável: econômica, social e ambiental (Figura 1).

\section{Figura 1 - Objetivos de Desenvolvimento Sustentável}

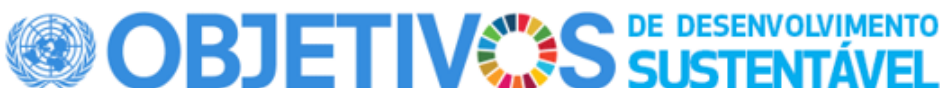
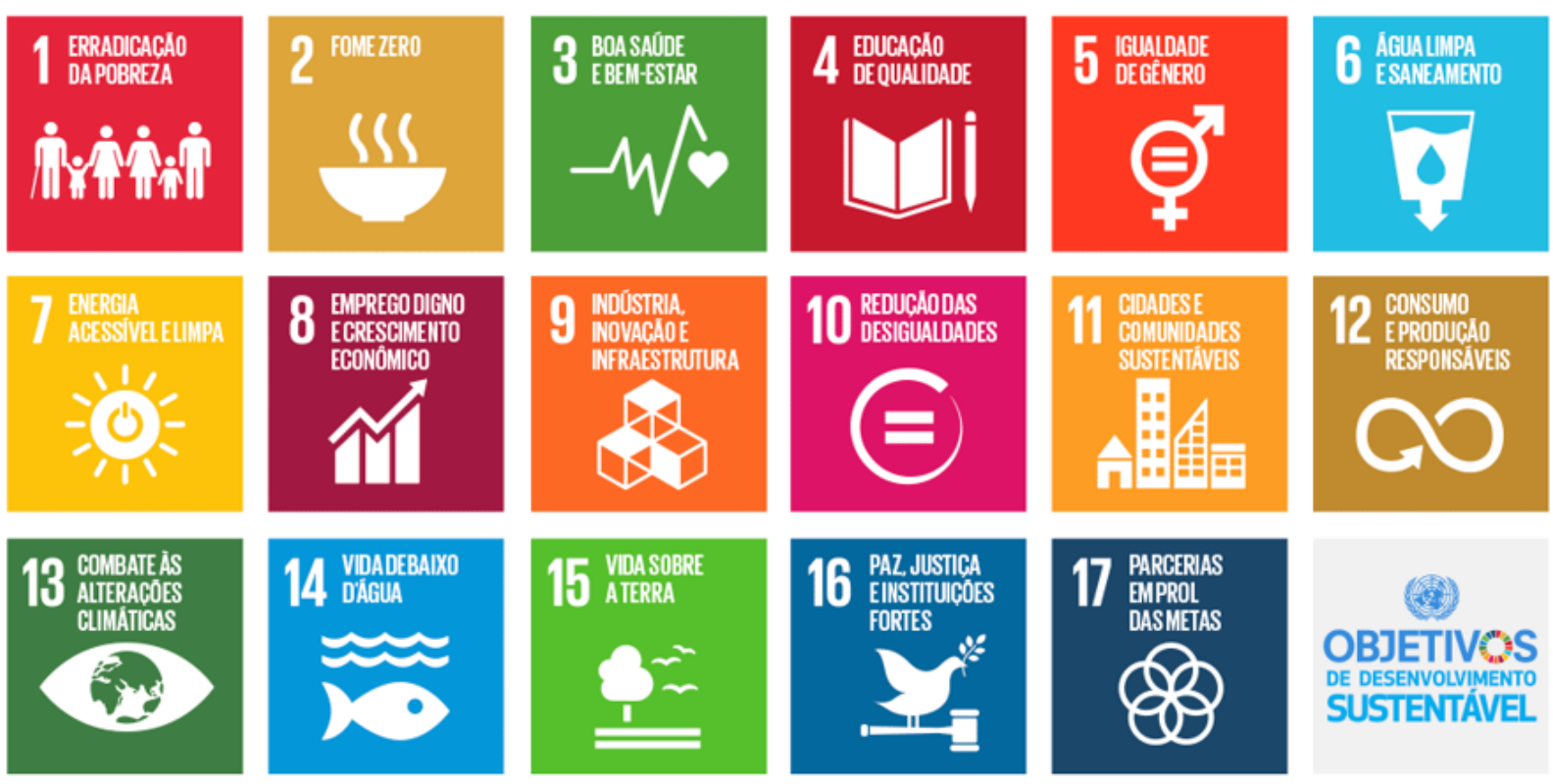

(68)

OBJETIVOS DE DESENVOLVIMENTO SUSTENTÁVEL

Fonte: ONU (2020).

Desde o estabelecimento da agenda, a ONU vem produzindo e divulgando diversos documentos, bem como realizando esforços para sensibilizar, esclarecer e motivar os agentes sociais (governos, empresas, sociedade civil etc.) a aderirem às metas. Um exemplo é o Roteiro para a Localização dos Objetivos de Desenvolvimento Sustentável (ONU, 2016), que visa prestar suporte a governos locais e regionais para a implementação da Agenda 2030 em âmbito local, com estratégias que podem ser adaptadas a contextos

1 Conferência das Nações Unidas sobre Desenvolvimento Sustentável, realizada entre 13 e 22 de junho de 2012, no Rio de Janeiro, com o objetivo principal de discutir e aperfeiçoar o compromisso político com o desenvolvimento sustentável do planeta. 2 Metas estabelecidas pela ONU em 2000, com o apoio de 191 países, que se comprometeram a uma nova parceria global para reduzir a pobreza extrema, em uma série de oito objetivos - com prazo para seu alcance em 2015. 
específicos e a necessidades de diferentes cidades e regiões. Outros são o Guia dos ODS para Empresas (GRI, ONU e WBCSD, 2015), com diretrizes para implementar os ODS na estratégia dos negócios e orientações ao setor privado nesse cenário, e Parcerias e Meios de Implementação (ONU, 2018).

O terceiro setor ocupa posição estratégica na concretização da Agenda 2030. Se, no passado, a sociedade civil se organizava a partir de questões humanistas envolvendo solidariedade, voluntarismo e ajuda ao próximo, liberdade e autonomia, hoje a realidade é muito mais abrangente. A própria diversificação e atuação das organizações não-governamentais (ONG), organizações da sociedade civil (OSC), instituições sem fins lucrativos (non-profit organizations - NPO, em inglês), entre outros termos, se transformaram na medida em que ocorreram a profusão e o fortalecimento dessas organizações, assim como suas relações com os demais atores da esfera pública foram intensificadas.

O resultado são ações de abrangência correlacionada aos limites e avanços do papel assumido por essas entidades como executoras de projetos e políticas de interesse público, ao aprimoramento de mecanismos de responsabilização, prestação de contas e transparência adotados pelo setor, acompanhamento de medidas do Estado e da Justiça, para além de muitos outros aspectos.

Nesse sentido, o presente artigo teve como objetivo verificar de que maneira as OSC têm identificado suas ações e atividades práticas com os ODS. Para isso, foi feita uma análise de como as organizações têm relacionado suas ações aos ODS no Mapa das OSC (IPEA, 2020). A plataforma instrumentaliza esse relacionamento, oferecendo um campo descritivo no qual é possível evidenciar o trabalho das OSC e seu impacto para a implementação dos ODS no país.

O texto está organizado em três partes principais. Nas primeiras, é feita uma breve discussão sobre como diversificação, organização e finalidade de atuação das OSC na atualidade coloca o setor como um ator social relevante para questões relacionadas ao desenvolvimento sustentável. Em seguida são apresentados os resultados obtidos. As considerações finais procuram retomar alguns pontos do artigo, indicando avanços e lacunas sobre a temática.

\section{AS OSC E OS ODS: CARACTERISTICAS CONVERGENTES E DIALỎGICAS}

$\mathrm{Na}$ atualidade, no Brasil, as OSC compõem um conjunto heterogêneo de entidades com características múltiplas de atuação e interação entre si, com o Estado, o mercado e os demais atores da sociedade civil, resultado do processo de redemocratização da sociedade brasileira. Isso faz com que a análise do papel desempenhado por elas seja complexa, contraditória e repleta de inflexões.

Em uma discussão sobre dados de transferências federais e projetos executados pelas OSC no Brasil, Mello, Pereira e Andrade (2019) pontuam que a interpretação do papel das OSC no país passa por três questões:

A primeira delas tem como cerne o antigo e polêmico debate sobre limites e possibilidades das relações entre Estado e OSC, em que são discutidos aspectos como dinâmicas de contraposição, relações de interdependência, autonomia e dependência das organizações. Em segundo lugar, é possível destacar análises dedicadas a compreender e detalhar a própria atuação das OSC, suas formas de gestão, seus mecanismos de financiamento, seu desenvolvimento de projetos, seus desafios e avanços recentes, bem como resultados, impactos gerados, entre outros. E, por último, ganha relevância a preocupação sobre a sustentabilidade das OSC, que, embora ainda esteja fortemente centrada na dimensão econômico-financeira, abarca uma ampla agenda de desafios e iniciativas em curso com potencial para influenciar o futuro dessas organizações no país (MELLO, PEREIRA e ANDRADE, 2019, p. 10). 
Nesse sentido, desafio parece ser a palavra-chave para estruturação, organização e atuação do setor. No caso dos ODS, especificamente, os desafios no Brasil são amplos e diversos e envolvem desde um contexto interno de múltiplas crises econômicas e políticas que atuam na contramão do desenvolvimento sustentável até o cenário mundial e a incapacidade de mobilização em prol da questão liderada pela própria ONU e alinhamento dos países membros às suas causas, bem como a aplicação prática de objetivos universais à realidade local.

Sobre essa última questão, o Ipea lançou, em 2018, um documento no qual apresenta uma proposta de adequação das metas globais da Agenda 2030 à realidade brasileira, na tentativa de orientar ações governamentais para formular e reformular políticas públicas e programas nacionais de desenvolvimento adequados ao contexto do território nacional, mantendo a abrangência e a ambição da proposta original.

\begin{abstract}
As características e especificidades da nação brasileira são tantas que, muitas vezes, não se veem representadas de maneira satisfatória em acordos globais. Em alguns casos, o Brasil já alcançou as metas estabelecidas; em outros, essas referem-se a problemas que não são observados internamente, ou não contemplam questões de grande relevância para o país. Ademais, na Federação brasileira, os compromissos com os ODS e com a implementação das políticas públicas requeridas para o seu alcance precisam ser assumidos e implementados nas suas três esferas: União, estados e municípios. É necessário, portanto, adaptar as metas de tal forma que os entes federados se sintam contemplados nas prioridades nacionais (IPEA, 2018, p. 13).
\end{abstract}

Diante desse cenário, as dificuldades encontradas para implementação e consolidação das relações globais e multilaterais voltadas para a promoção dos ODS não são exclusivas das OSC - se aplicam, em maior ou menor grau, a todos os setores da sociedade. Simultaneamente, verifica-se um diálogo e a convergência das finalidades de atuação das OSC com as metas contempladas nos ODS, o que coloca as organizações na função de ator social relevante - e, por que não, protagonista - na implantação da Agenda.

Dados do Mapa das OSC mostram que, das organizações em atividade no Brasil até 2016 (820.186 no total), desenvolvimento e defesa de direitos e interesses e organizações religiosas são os principais grupos de OSC no país e representam mais de seis em cada dez organizações em atividade. As 339.104 organizações ligadas à defesa de direitos e interesses são 41,3\% do total, enquanto as 208.325 mil OSC com finalidades religiosas são 25,4\%. Na sequência, aparecem: cultura e recreação (79.917 ou 9,7\%); outras atividades associativas (77.550 ou 9,5\%); educação e pesquisa (39.669, ou 4,8\%); assistência social (27.383 ou 3,3\%); associações patronais e profissionais (22.261 ou 2,7\%); outras organizações da sociedade civil (19.136 ou 2,3\%); e saúde (6.841 ou 0,8\%) (LOPEZ, 2018, p. 38-39).

Algumas iniciativas já se repercutem, em especial a divulgação de estudos que, de certa maneira, baseiam ações direcionadas para o setor, apoiam gestores públicos a definirem políticas mais efetivas em parcerias com as OSC e fomentam a agenda de novas pesquisas sobre o tema das OSC e ODS, como é o caso deste trabalho. "Um debate público de qualidade requer dados consistentes para apoiar narrativas mais realistas sobre os papéis das OSC no país, que suplantem imagens difundidas em análises parciais ou preconceitos pouco fundamentados" (LOPEZ, 2018, p. 9).

Uma das ações conhecidas é a criação do Grupo de Trabalho da Sociedade Civil para a Agenda 2030 (GTSC A2030, 2017), composto por mais de 40 participantes, entre ONG, movimentos sociais, fóruns e fundações brasileiras. O grupo é resultado do encontro entre organizações que estavam acompanhando a agenda pós-2015 e seus desdobramentos e, desde então, tem atuado no seguimento da implementação e monitoramento dos ODS 3 .

3 Inicialmente facilitado pela Associação Brasileira de ONG em defesa de direitos e bens comuns (Abong) e pela Gestos Soropositividade, Comunicação e Gênero, o grupo de trabalho foi formalizado em 2014, ainda durante as negociações da Agenda 2030 (GTSC A2030, 2017, p. 4). 
Em 2017, o GTSC A2030 divulgou um documento no qual chama a atenção para o fato de que poucos foram os passos dados para a implementação dos ODS no país. Cita como avanços a criação da Comissão Nacional dos ODS em 2016, uma das reivindicações do próprio grupo, e a instalação de uma Frente Parlamentar Mista de Apoio aos ODS, também a partir da demanda de OSC, com o objetivo de discutir e propor medidas que reforcem os meios de implementação da agenda. No entanto, segundo o documento, tais medidas não são suficientes para o cumprimento das metas estabelecidas, além de haver retrocessos.

Os dados analisados refletem um processo de negligência do bem público em nome da manutenção do status quo e de desmonte das políticas voltadas à promoção da dignidade, redução das desigualdades, efetivação de direitos humanos e sustentabilidade socioambiental, frutos de décadas de construção e conquistas da sociedade (GTSC A2030, 2017, p. 3).

Nesse sentido, enfatiza que

Os resultados são extremamente preocupantes diante dos desafios de erradicar a pobreza e eliminar a fome, assegurar a inclusão socioprodutiva, garantir uma vida saudável, alcançar a equidade de gênero, construir infraestrutura resiliente e acessível a todas as pessoas, promover industrialização inclusiva e sustentável, estimular a inovação e proteger os ecossistemas marinhos (GTSC A2030, 2017, p. 2).

Outra ação é a terceira edição do Perfil do Profissional pelo Desenvolvimento Sustentável (ABRAPS, 2017), que contempla dados sobre os ODS, lançada em 2017. O texto destaca que todos os ODS são, de alguma forma, trabalhados pelos 244 respondentes da pesquisa, ainda que indiretamente (sendo que, desse total, $23 \%$ representam entidades do terceiro setor). Quando perguntados quais ODS são trabalhados, foram dadas as seguintes respostas: ODS-3 boa saúde e bem-estar, 1 entidade; ODS-4 educação de qualidade, 1 entidade; ODS-6 água limpa e saneamento, 1 entidade; ODS-7 energia acessível e limpa, 2 entidades; ODS-8 emprego e crescimento econômico, 2 entidades; ODS-9 indústria, inovação e infraestrutura, 1 entidade; ODS-11 cidades e comunidades sustentáveis, 1 entidade; ODS-12 consumo e produção sustentáveis, 3 entidades; ODS-13 combate às alterações climáticas, 2 entidades; ODS-14 vida debaixo da água, 1 entidade; ODS-17 parcerias em prol de metas, 2 entidades; todos os ODS, 3 entidades.

Há ainda o relatório Benchmark do Investimento Social Corporativo (BISC), sobre os compromissos do setor privado com a atuação social (COMUNITAS, 2016). Especificamente nessa edição, o tema de destaque foram as possibilidades de conexão dos investimentos sociais privados à Agenda 2030. Os dados apontam para um cenário de favorável, uma vez que os projetos sociais e ambientais em curso teriam potencial de contribuir para o alcance dos ODS, inclusive com as empresas dispostas a explorar as possibilidades de trabalhar nessa direção.

O estudo identificou áreas de convergência com a atuação das empresas no campo social, entre elas: ODS-1 erradicação da pobreza; ODS-2 erradicação da fome; ODS-3 promoção da saúde; ODS-4 educação de qualidade; e ODS-11 cidades e comunidades sustentáveis. Porém, questiona:

Essa identificação de áreas de convergência será suficiente para levar as empresas a adotar a Agenda 2030 como norteadora de seus investimentos sociais? O que seria necessário para promover esse alinhamento?

$[\ldots]$

Pelas informações captadas no BISC, o que pode mover o grupo nessa direção é a percepção dos impactos positivos dos ODS para o planeta, o reconhecimento de que o setor privado pode contribuir para esse desafio global e a importância atribuída pela sociedade ao tema [...]. Nesse sentido, fica o alerta de que as empresas se envolverão mais na medida em que a sociedade estiver mobilizada e pressione efetivamente o setor privado por sua adesão (COMUNITAS, 2016, p. 104). 
Como conclusão principal, o relatório aponta que a maioria das empresas consultadas já assumiu compromissos públicos com a Agenda 2030, por meio de documentos oficiais ou da participação em outras iniciativas relacionadas ao tema. No entanto, isso não significa que eles foram incorporados às estratégias dos negócios ou de condução dos investimentos sociais, até mesmo por uma questão, na época, de tempo hábil (COMUNITAS, 2016, p. 142).

A edição de 2019 do mesmo relatório contou com algumas atualizações referentes aos compromissos do setor privado com os ODS, questionando: "O que o grupo BISC está fazendo para incorporar os ODS na agenda dos investimentos sociais? E quais as maiores dificuldades para integrar os investimentos sociais aos ODS?" Sobre a primeira pergunta, aponta o documento que, para incorporar as dimensões contempladas nos ODS à agenda dos investimentos sociais, mais empresas e, sobretudo, mais institutos não mencionados na edição de 2016 estão se dedicando a identificar as possíveis conexões dos seus projetos com os 17 ODS e a promover debates sobre o tema. Merece destaque o fato de que $44 \%$ das empresas estabeleceram metas para seus projetos sociais conectadas às metas dos ODS; e $71 \%$ dos institutos promoveram capacitação de equipes para gerir projetos sociais integrados aos ODS. Já sobre a segunda, indica que definir metas conectadas aos ODS e medir resultados permanecem entre as principais dificuldades enfrentadas pelo grupo. Não obstante, na medida em que as empresas vão buscando adotar a Agenda 2030, modifica-se a percepção sobre os desafios a serem superados (COMUNITAS, 2019).

Destaca-se, também, alguns dados dos censos elaborados pelo Grupo de Institutos, Fundações e Empresas (GIFE). A edição de 2016 já trouxe informações sobre a identificação dos associados com os ODS. Porém, a edição de 2018, mais atualizada, revelou que $72 \%$ dos institutos e fundações e $34 \%$ de institutos e fundações familiares consultados consideram os ODS como referência para suas estratégias. Somente $1 \%$ dos respondentes não apresentaram familiaridade com a temática. Além disso, os ODS mais incorporados pelos respondentes foram: ODS-4 educação de qualidade; ODS-8 trabalho decente e crescimento econômico; e ODS-10 redução das desigualdades. Os menos citados foram: ODS-7 energia limpa e acessível; ODS-14 vida na água; e ODS-15 vida terrestre (GIFE, 2019).

Por fim, inúmeras ações práticas, que não necessariamente rendem dados sistematizados sobre a relação ODS e OSC, têm o objetivo de disseminar o tema e conscientizar as OSC da importância da questão. Apenas para citar dois exemplos: a Escola Aberta do Terceiro Setor gravou, em 2019, um curso virtual completo especialmente dedicado ao tema da Agenda 2030 - cada aula, disponibilizada gratuitamente na plataforma da Escola, abordou um ODS diferente (ESCOLA, 2019); e o Movimento Nacional dos ODS Paraná promove, mensalmente, reuniões gratuitas para prestar esclarecimentos e orientações sobre a Agenda 2030 a diversos públicos, incluindo OSC (FIEPR, 2019).

\section{MAPA DAS OSC COMO INDICATIVO DO TRABALHO DAS ORGANIZAÇÕES JUNTO AOS ODS}

O Mapa das Organizações da Sociedade Civil (IPEA, 2020) é uma plataforma online, georreferenciada, de transparência pública. Foi lançado em 2016, com base no Decreto Federal 8.726, que regulamenta a Lei Federal 13.019 (BRASIL, 2014), conhecida como Marco Regulatório das Organizações da Sociedade Civil (MROSC) ${ }^{4}$. Tem como objetivos principais: dar transparência à atuação das OSC, principalmente às ações executadas em parceria com a administração pública; informar mais e melhor sobre a importância e diversidade de projetos e atividades conduzidas por essas organizações; disponibilizar dados e fomentar pesquisas sobre OSC; acompanhar a implementação do MROSC na União, estados, Distrito Federal e municípios; e apoiar os gestores públicos na tomada de decisões sobre políticas públicas que já têm ou possam ter interface com OSC.

\footnotetext{
4 A Lei 13.019/2014 entrou em vigor para a União, estados e Distrito Federal em janeiro de 2016 e, para municípios, em janeiro de 2017. Trata-se de um conjunto de medidas voltado para o aperfeiçoamento da relação entre as OSC e o Estado que estabelece um regime jurídico para celebração de parcerias, estimula a gestão pública democrática e valoriza as organizações enquanto parceiras na garantia e efetivação de direitos.
} 
Gerenciado pelo Instituto de Pesquisa Econômica Aplicada (IPEA), o Mapa é abastecido a partir de duas frentes: um sistema informatizado que capta, limpa, sistematiza e disponibiliza informações provenientes da base de dados públicas, especialmente a Relação Anual de Informação Social (RAIS) e a Secretaria da Receita Federal do Brasil (SRFB); e informações que a própria OSC insere, mediante cadastro gratuito de representante, conforme seus interesses.

Os dados são disponibilizados a qualquer usuário via web, em formato de lista (visualizada online ou disponível para download em Excel) ou na página individual de cada organização - o sistema gera gratuitamente um uniform resource locator (URL) próprio para cada OSC -, organizada a partir de um formulário com campos de preenchimento. As informações reunidas sobre cada uma delas são as mais variadas possíveis: localização, finalidades de atuação, natureza jurídica, número de funcionários, dados sobre recebimento de recursos públicos etc. O Cadastro Nacional de Pessoa Jurídica (CNPJ) é a chave de todo o processo de indexação, revelando que só as instituições constituídas formal e juridicamente são incluídas.

Em 2017, uma parceria entre o Ipea e o Programa das Nações Unidas para o Desenvolvimento (PNUD) permitiu que a OSC, ao preencher seus dados no Mapa, relacionasse suas ações e atividades com os ODS. A medida, pelo lado do Ipea, teve como objetivo favorecer arranjos institucionais para melhorar a capacidade de mobilização e influência das organizações perante os demais públicos, visando o aumento da base de dados, a qualificação das informações e a produção de melhores relatos sobre o campo da sociedade civil organizada no país. Pelo lado do PNUD, tratou-se de mais um acordo de cooperação para dar amplitude à Agenda 2030 e garantir sua implementação (PNUD, 2017).

Dessa maneira, o formulário que cada OSC preenche virtualmente (Figura 2) passou a contar com um campo que possibilita à OSC escolher, dentre os 17 ODS e suas respectivas metas (um total de 169), as opções que melhor se identificam com as atividades desenvolvidas. Cada OSC pode relacionar suas ações a até três ODS e respectivas metas.

Figura 2 - Formulário para OSC escolher os ODS de acordo com as atividades desenvolvidas

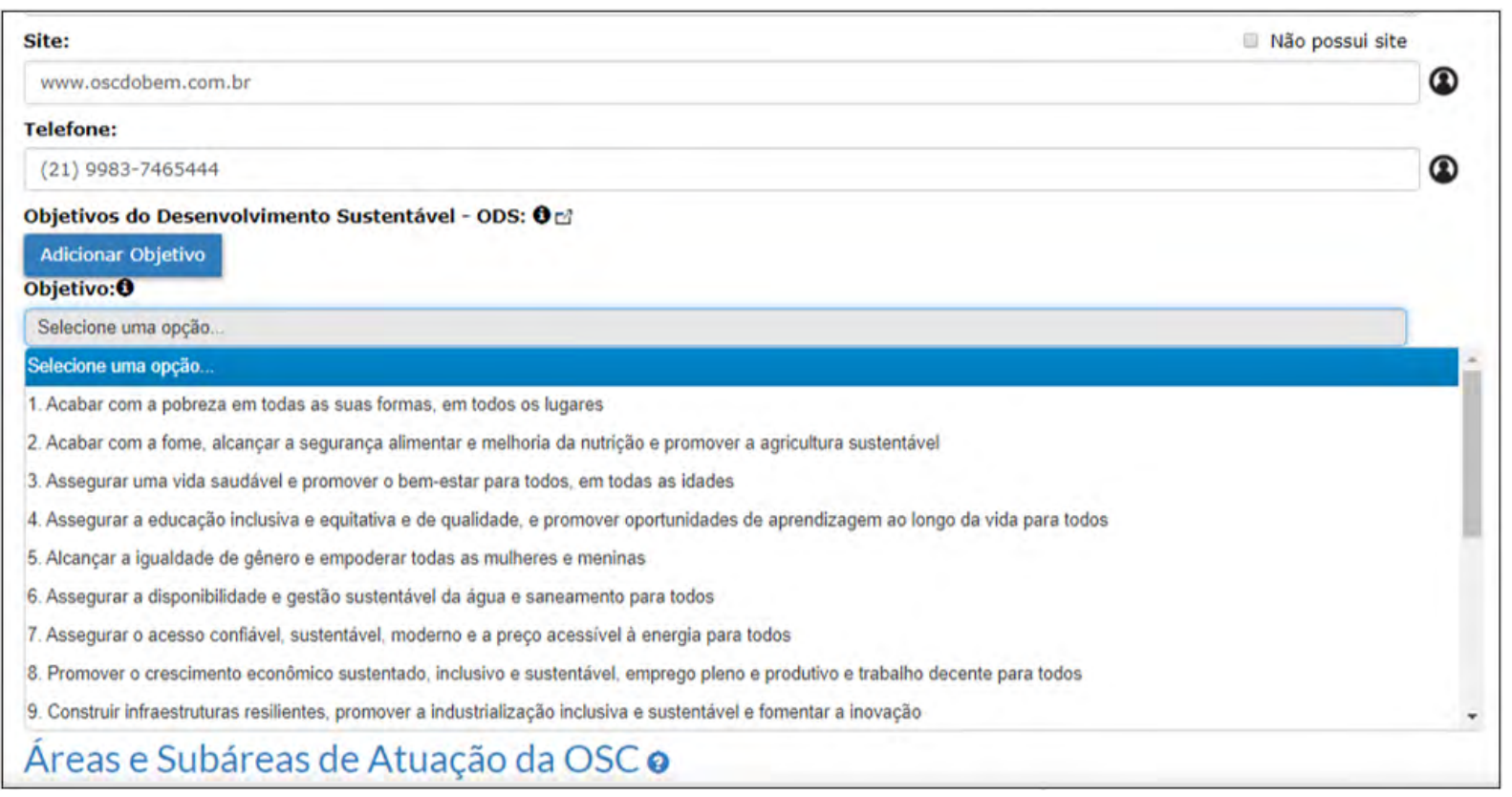

Fonte: Ipea (2020) 


\section{Figura 3 - Formulário para OSC escolher metas relacionadas aos ODS escolhidos}

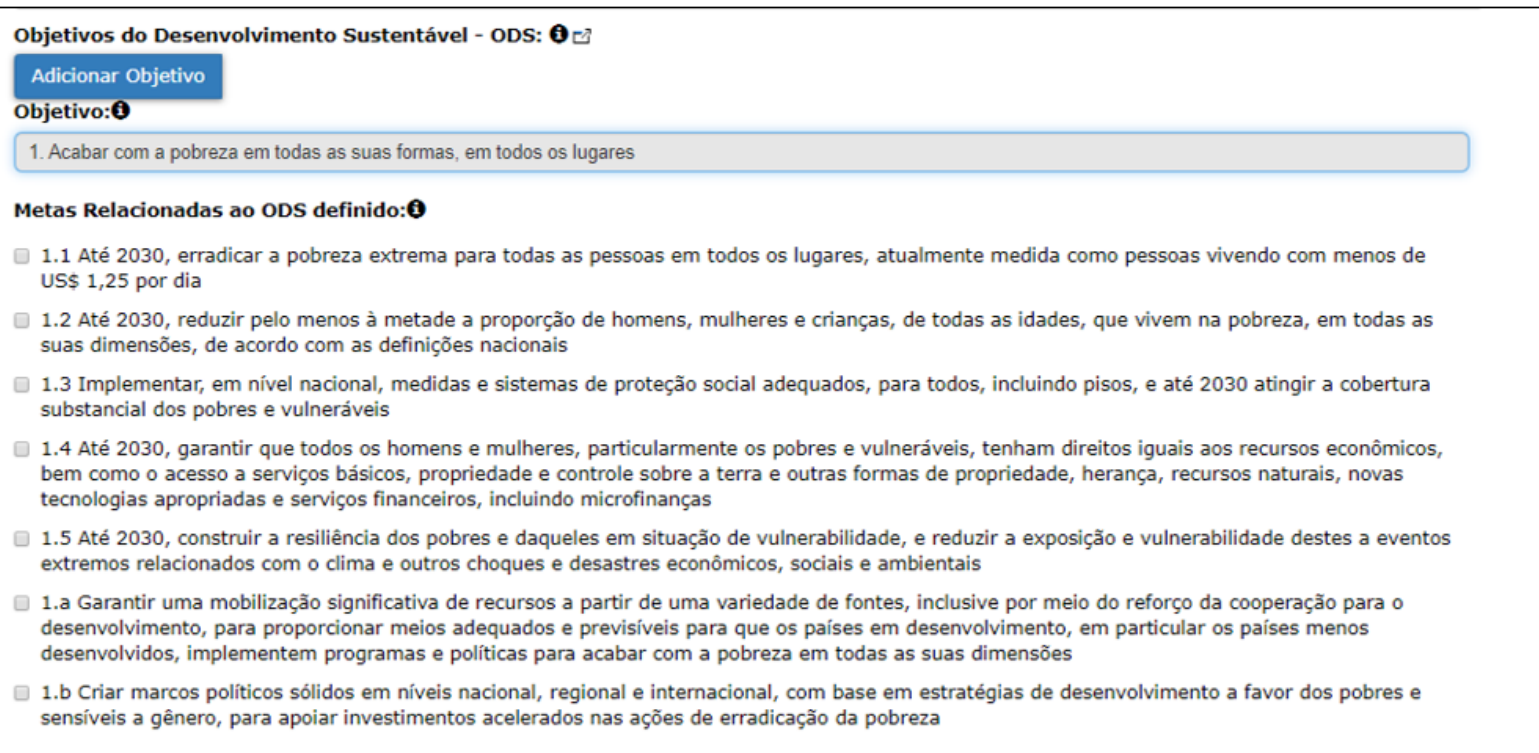

Fonte: Ipea (2020)

O preenchimento dos ODS no Mapa é facultativo às OSC, de acordo com seus interesses, condições de acesso à internet e à plataforma, realização de cadastro de representante - instantâneo e gratuito, mas relacionado à conscientização das entidades da importância da inserção e constante atualização dos dados em suas páginas virtuais individuais -, entre outros fatores. Ou seja, não há obrigatoriedade de relacionar as atividades aos ODS, nem um sistema automático para incluir esses dados.

\section{A IDENTIFICAÇÃO DAS OSC COM OS ODS}

Este trabalho levantou todas as OSC que preencheram o campo ODS até julho de 2019, um total de 2.040 instituições $^{5}$. Os principais objetivos foram: verificar a contemplação dos ODS e respectivas metas por parte das organizações; e 2) examinar a localização geográfica e as áreas de atuação das OSC que preencheram os ODS.

Os resultados revelaram que, majoritariamente, as OSC identificam suas atividades ao ODS-4 educação de qualidade (510 registros). Na sequência, destacam-se: ODS-16 paz e justiça (211 registros); ODS-3 saúde de qualidade (183 registros); e ODS-15 vida sobre a terra (164 registros). Os menos contemplados são: ODS-9 inovação e infraestrutura, ODS-6 água limpa e saneamento e ODS-7 energias renováveis, respectivamente, com 35, 31 e 7 registros (Tabela 1).

5 A base de dados foi fornecida pela própria equipe do Mapa, via contato direto. 


\section{Tabela 1 - ODS contemplados pelas OSC, quantitativamente, no Mapa das OSC}

\section{ODSN. DESCRIÇÃO}

QUANTIDADE

$1 \quad$ Erradicação da pobreza $\quad 145$

$2 \quad$ Erradicação da fome $\quad 92$

$3 \quad$ Saúde de qualidade 183

$\begin{array}{llll}4 & \text { Educação de qualidade } & 510\end{array}$

$5 \quad$ Igualdade de gênero 158

$6 \quad$ Água limpa e saneamento $\quad 31$

\begin{tabular}{l|l|r}
7 & Energias renováveis & 7
\end{tabular}

$8 \quad$ Empregos dignos e crescimento econômico $\quad 118$

$9 \quad$ Inovação e infraestrutura $\quad 35$

10 Redução das desigualdades $\quad 81$

11 Cidades e comunidades sustentáveis $\quad 73$

12 Consumo responsável 7 : 75

13 Combate às mudanças climáticas $\quad 25$

14 Vida debaixo da água 78

15 Vida sobre a terra 164

16 Paz e justiça $\quad 211$

\begin{tabular}{l|l|r}
17 & Parcerias pelas metas & 54
\end{tabular}

TOTAL $\quad \mathbf{2 . 0 4 0}$

Fonte: Ipea (2020). Elaboração própria.

Ao verificar a finalidade de atuação das $\mathrm{OSC}^{6}$, percebe-se que a maioria das organizações que fez a relação de suas principais atividades aos ODS no Mapa (Tabela 2) trabalha com desenvolvimento e defesa de direitos (565) e assistência social (431). A finalidade de educação e pesquisa aparece em terceiro (281). Meio ambiente e proteção animal ocupa o sexto lugar (118) e saúde, a oitava posição (96).

Apesar de o Mapa prever uma classificação por finalidade de atuação, sabe-se que as OSC apresentam grande diversidade em seus objetivos organizacionais, o que dificulta uma classificação em grupos conceitualmente razoáveis e empiricamente realistas (LOPEZ, 2018). No caso dos dados apresentados, chama a atenção a identificação de ODS por OSC que têm outras finalidades que não a de educação e pesquisa (categoria adotada pelo Mapa), com o ODS-4 educação de qualidade - a quantidade de registros de organizações com essa finalidade de atuação (510 no total) ultrapassa a quantidade de instituições que se identificaram especificamente ao ODS-4 (281). Trata-se de mais um indicativo da necessidade de se compreender os espaços de participação social nos quais as OSC atuam e os ODS se inserem.

6 O Mapa delimita as finalidades de atuação das OSC no Brasil com base nos princípios da atividade principal estabelecidos pela Classificação Nacional de Atividades Econômicas (CNAE) - a classificação oficial do sistema estatístico nacional, que padroniza os códigos de atividades econômicas para a produção de informações estatísticas e sua derivada, a CNAESubclasses, amplamente utilizada nos cadastros e registros administrativos do país. 
Tabela 2 - OSC, por finalidade de atuação, que relacionaram suas atividades aos ODS no Mapa

FINALIDADE DE ATUAÇÃO

QUANTIDADE

Desenvolvimento e defesa de direitos $\quad 565$

Assistência social $\quad 431$

Educação e pesquisa $\quad-\quad 281$

\begin{tabular}{l|l} 
Cultura e recreação & 199
\end{tabular}

\begin{tabular}{l|r} 
Outras atividades associativas & 168
\end{tabular}

Meio ambiente e proteção animal $\quad$ : 118

\begin{tabular}{ll|r} 
Outros & 98
\end{tabular}

Saúde $\quad 96$

Religião $\quad 51$

Habitação

\begin{tabular}{l|r}
\hline Associações patronais e profissionais & 14
\end{tabular}

TOTAL

Fonte: Ipea (2020). Elaboração própria.

Com relação às metas relacionadas a cada ODS, dentro do ODS mais contemplado - ODS-4 educação de qualidade -, a que mais se identifica com as atividades desenvolvidas pelas OSC é a meta 4.7 (com 115 registros):

Meta 4.7 - Até 2030, garantir que todos os alunos adquiram conhecimentos e habilidades necessárias para promover o desenvolvimento sustentável, inclusive, entre outros, por meio da educação para o desenvolvimento sustentável e estilos de vida sustentáveis, direitos humanos, igualdade de gênero, promoção de uma cultura de paz e não violência, cidadania global e valorização da diversidade cultural e da contribuição da cultura para o desenvolvimento sustentável (ONU, 2020).

Dentro desse mesmo ODS, a meta menos contemplada é a 4.b, com 11 registros:

Meta 4.b - Até 2020, substancialmente ampliar globalmente o número de bolsas de estudo para os países em desenvolvimento, em particular os países menos desenvolvidos, pequenos Estados insulares em desenvolvimento e os países africanos, para o ensino superior, incluindo programas de formação profissional, de tecnologia da informação e da comunicação, técnicos, de engenharia e programas científicos em países desenvolvidos e outros países em desenvolvimento (ONU, 2020).

Já com relação ao ODS menos marcado quantitativamente pelas OSC - ODS-7 energias renováveis -, as metas 7.2 e 7.a são as mais seguidas, com 3 registros cada, respectivamente:

Meta 7.2 - Até 2030, aumentar substancialmente a participação de energias renováveis na matriz energética global.

Meta 7.a - Até 2030, reforçar a cooperação internacional para facilitar o acesso a pesquisa e tecnologias de energia limpa, incluindo energias renováveis, eficiência energética e tecnologias de combustíveis fósseis avançadas e mais limpas, e promover o investimento em infraestrutura de energia e em tecnologias de energia limpa (ONU, 2020).

Há ainda metas que contém registro zero, conforme a Tabela 3. 


\section{Tabela 3 - Metas dos ODS mais e menos contempladas pelas OSC no Mapa}

ODS META MAIS MENCIONADA META MENOS MENCIONADA

N.

QTD. (") N.

QTD. (")

\begin{tabular}{|c|c|c|c|c|}
\hline 1 & 1.4 & 32 & 1.3 & 11 \\
\hline 2 & 2.1 & 34 & 2.b & 2 \\
\hline 3 & 3.5 & 35 & 3.9 & 2 \\
\hline 4 & 4.7 & 115 & 4.b & 11 \\
\hline 5 & 5.5 & 31 & 5.4 & 7 \\
\hline 6 & 6.b & 13 & $6.2,6 . a$ & 0 \\
\hline 7 & 7.2,7.a & 3 & 7.1, 7.3 & 0 \\
\hline 8 & 8.3 & 20 & 8.10 & 1 \\
\hline 9 & 9.5 & 7 & $9 . a$ & 0 \\
\hline 10 & 10.2 & 41 & 10.5, 10.7, 10.a, 10.c & 0 \\
\hline 11 & 11.7 & 16 & 11.1 e $11 . c$ & 2 \\
\hline 12 & 12.2 & 15 & 12.7 & 1 \\
\hline 13 & 13.3 & 9 & 13.1, 13.2, 13.a, 13.b & 4 \\
\hline 14 & 14.1, 14.2, 14.c & 11 & 14.3, 14.6, 14.7 & 4 \\
\hline 15 & $15 . a$ & 23 & $15.4,15.8$ & 7 \\
\hline 16 & 16.7 & 33 & 16.4 & 5 \\
\hline 17 & 17.7 & 13 & 17.2, 17.4, 17.5, 17.9, 17.10, 17.11, 17.13 & 0 \\
\hline & TOTAL & 451 & TOTAL & 57 \\
\hline
\end{tabular}

Fonte: Ipea (2020). Elaboração própria

Nota: (*) Quantidade. Quando há mais de uma meta relacionada, a quantidade indicada é para cada uma.

Uma hipótese para a existência de metas não contempladas (com registros iguais a zero, na Tabela 3) é a grande quantidade de metas e variedade de opções relacionadas aos ODS - no total são 169 -, que podem gerar confusão por parte da OSC na hora do preenchimento. O ODS-17, por exemplo, é o que mais tem metas (19 no total) e, pelos registros, o que mais tem metas com preenchimento zero (7 no total). Além disso, há termos na descrição de cada meta que nem sempre são de conhecimento comum, têm definição prática ou podem ser mensurados, variáveis que tendem a dificultar o processo de identificação. Alguns exemplos: "cobertura substancial” (meta 1.3), "marcos políticos sólidos" (meta 1.b), "práticas agrícolas resilientes" (meta 2.4), "fortalecer a implementação da convenção-quadro para o controle do tabaco (meta 3.a), "programa de ação da Conferência Internacional sobre População e Desenvolvimento e com a Plataforma de Ação de Pequim" (meta 5.6), "plano decenal de programas sobre produção e consumo sustentáveis” (meta 8.4), entre outros.

Por fim, com relação à distribuição geográfica (Tabela 4), as OSC com sede na região Sudeste são as que mais identificam suas atividades aos ODS (1.248 registros). Na sequência, estão a região Sul (245), Centro-Oeste (209), Norte (178) e Nordeste (160). A maioria tem sede nos estados de São Paulo (821) e Rio de Janeiro (244). Amapá, Tocantins e Alagoas não têm registros. Uma curiosidade é que 1.231 OSC têm sede nas capitais dos estados: a maior quantidade em São Paulo (443) e Rio de Janeiro (219) e nenhuma em Pernambuco, Maceió, Macapá e Palmas. 
Tabela 4 - Localização das OSC que relacionam suas atividades aos ODS no Mapa

UF

QUANTIDADE OSC

NORDESTE

160

Alagoas

Bahia

Ceará

Maceió

33

Paraíba

26

Piauí

24

Pernambuco

8

Rio Grande do Norte

Sergipe

SUDESTE

1.248

São Paulo

Rio de Janeiro

244

Minas Gerais 143

Espírito Santo

40

SUL

Rio Grande do Sul

Paraná 185

Santa Catarina

CENTRO-OESTE

209

Goiás

32

Mato Grosso

86

Mato Grosso do Sul

Distrito Federal

4

NORTE

178

Acre

4

Amapá

Amazonas

0

\begin{tabular}{lll} 
Pará & 93 \\
\hline & 33
\end{tabular}

Rondônia 24

Roraima 24

Tocantins

TOTAL

Fonte: Ipea (2020). Elaboração própria 


\section{CONSIDERAÇÕES FINAIS}

Tanto as questões sobre OSC quanto ODS abordadas neste artigo, bem como a relação entre as duas temáticas, mostram a heterogeneidade inerente ao desenvolvimento sustentável e ao campo de ações da sociedade civil organizada, seus aspectos definidores e os avanços e limites associados ao terceiro setor. Soma-se a isso o grau de autonomia das organizações, bem como a variedade e ambição das metas da Agenda 2030, em um complexo cenário, que depende ainda de outros atores sociais, como governos, empresas etc., nas esferas nacionais e internacionais.

Pelos dados coletados, percebe-se uma clara compatibilidade entre as finalidades de atuação das OSC classificadas pelo Mapa e as propostas dos ODS. Registrou-se que os ODS mais trabalhados pelas organizações declarantes são o ODS-4 educação de qualidade (510 registros), seguido do ODS-16 paz e justiça (211 registros). Por outro lado, o menos contemplado é o ODS-7 energias renováveis ( 7 registros).

Além disso, verificou-se um protagonismo das OSC com sede na região Sudeste na identificação das ações à Agenda 2030, com 1.248 registros, contra apenas 160 registros identificados na região Nordeste, revelando uma geografia desigual que vai ao encontro de questões econômicas, históricas e sociais da constituição regional do Estado brasileiro. Cinco $\operatorname{ODS}$ (6, 7, 9, 10 e 17) ainda não são contemplados em sua plenitude pelo terceiro setor, com metas preenchidas iguais a zero.

Tais números mostram um cenário de avanços e limitações. O primeiro diz respeito à identificação de dados iniciais, porém sistematizados, que permitem uma melhor compreensão da realidade e oferecem uma perspectiva organizadora dos elementos que caracterizam as interações entre OSC e ODS. O segundo remete a questões de participação das OSC na temática e a própria estruturação do setor, o que envolve mobilização e sensibilização mais efetiva a causas de maior amplitude, que ultrapassam a proximidade de seus territórios e públicos específicos e apontam para a necessidade de uma conscientização social mais dinâmica, flexível e aberta, ainda que localizada em meio às inúmeras dificuldades do cotidiano enfrentadas pelas instituições.

Nesse sentido, entender como as OSC brasileiras têm direcionado suas atividades para a contemplação dos ODS é tarefa urgente para o reconhecimento da diversidade e relevância de ações de interesse público e aumenta a chance de replicar boas práticas registradas e avanços na questão. O Mapa das OSC, ainda que com dados preenchidos quantitativamente modestos se comparados ao universo de organizações mapeadas, se apresentou como um instrumento concreto para a sistematização desse conhecimento, capaz de oferecer material sobre a Agenda 2030 e ODS para a incidência (advocacy) local sobre ODS nesse aspecto. 


\section{REFERÊNCIAS}

ABRAPS - Associação Brasileira dos Profissionais pelo Desenvolvimento Sustentável. Perfil do Profissional pelo Desenvolvimento Sustentável. 2017. Disponível em: http://abraps.org.br/ods/. Acesso em: 4 nov. 2019.

BRASIL. Lei 13.019, de 31 de julho de 2014. Marco regulatório das organizações da sociedade civil. Brasília, Secretaria Geral da Presidência da República, 2014. Disponível em: http://www.planalto.gov. br/ccivil_03/_ato2011-2014/2014/lei/113019.htm. Acesso em: 8 set. 2020.

COMUNITAS. BISC - Benchmark do Investimento Social Corporativo. Destaques 2019. 2019. Disponível em: https://bisc.org.br/bisc-2019/os-investimentos-sociais-e-os-direitos-humanos-na-politicacorporativa-de-sustentabilidade/. Acesso em: 5 nov. 2019.

COMUNITAS. BISC - Benchmark do Investimento Social Corporativo. Relatório. 2016. Disponível em: https://sinapse.gife.org.br/download/relatorio-bisc-2016. Acesso em: 8 set. 2020.

ESCOLA Aberta do Terceiro Setor, 2019. Disponível em: https://www.escolaaberta3setor.org.br. Acesso em: 8 set. 2020.

FIEPR - Federação das Indústrias do Estado do Paraná. Nós podemos. 2019. Disponível em: http:// www.fiepr.org.br/nospodemosparana. Acesso em: 8 set. 2019.

GIFE - Grupo de Instituições, Fundações e Empresas. Censo GIFE 2018. Mosaico Portal de Dados do Investimento Social. 2019. Disponível em: https://mosaico.gife.org.br/censo-gife/temas/focos-deatuacao/32-alinhamento-aos-ods. Acesso em: 27 set. 2020.

GRI - Global Reporting Initiative; ONU - Organização das Nações Unidas; WBCSD - World Business Council for Sustainable Development. Guia dos ODS para Empresas. 2015. Disponível em: https:// cebds.org/wp-content/uploads/2015/11/Guia-dos-ODS.pdf. Acesso em: 4 nov. 2019.

GTSC A2030 - Grupo de Trabalho da Sociedade Civil para Agenda 2030. Relatório luz da Agenda 2030 de desenvolvimento sustentável: síntese. 2017. Disponível em: http://actionaid.org.br/wp-content/ files_mf/1499785232Relatorio_sintese_v2_23jun.pdf. Acesso em: 5 nov. 2019.

IPEA - Instituto de Pesquisa Econômica Aplicada. AGENDA 2030: Objetivos de Desenvolvimento Sustentável, proposta de metas brasileiras. Brasília: Ipea, 2018.

IPEA - Instituto de Pesquisa Econômica Aplicada. Mapa das OSC. 2020. Disponível em: https:// mapaosc.ipea.gov.br. Acesso em: 8 set. 2020.

LOPEZ, F. G. (org.). Perfil das organizações da sociedade civil no Brasil. Brasília: Ipea, 2018.

MELLO, J.; PEREIRA, A. C. R.; ANDRADE, P. G. Afinal, o que os dados mostram sobre a atuação das ONGs? Análise de transferências federais e projetos executados pelas Organizações da Sociedade Civil no Brasil. Texto para discussão. Rio de Janeiro e Brasília: Ipea, 2019.

ONU - Organização das Nações Unidas. Movimento de ação global para as pessoas e o planeta. 2020. Disponível em: https://nacoesunidas.org/pos2015. Acesso em: 8 set. 2020.

ONU - Organização das Nações Unidas. Parcerias e meios de implementação: fortalecer os meios de implementação e revitalizar a parceria global para o desenvolvimento sustentável. 2018. Disponível em: https://nacoesunidas.org/pos2015/ods17/. Acesso em: 04 nov. 2019. 
ONU - Organização das Nações Unidas. Roteiro para a localização dos Objetivos de Desenvolvimento Sustentável: implementação e acompanhamento no nível subnacional. 2016. Disponível em: https:// nacoesunidas.org/wp-content/uploads/2017/06/Roteiro-para-a-Localizacao-dos-ODS.pdf. Acesso em: 4 nov. 2019.

PNUD - Programa das Nações Unidas para o Desenvolvimento. Nota conceitual da parceria PNUD e Mapa das OSC. 2017. 


\section{A AUTORA}

\section{Camila Escudero \\ camilaescudero@uol.com.br/ camila.escudero@ipea.gov.br}

Doutora em Comunicação e Cultura pela Universidade Federal do Rio de Janeiro (UFRJ). Assistente de pesquisa do Instituto de Pesquisa Econômica Aplicada (Ipea) no projeto Mapa das OSC. Professora do Programa de Pós-Graduação em Comunicação da Universidade Metodista de São Paulo. 


\title{
artigos GIFE
}

Supervisão: José Marcelo Zacchi e Gustavo Bernardino

Coordenação: Carolina Magosso

Produção editorial: Gleice Regina Guerra

Apoio: Graziela Santiago

Comitê de seleção: Ana Lúcia D'Império Lima, Fábio Silva

Tsunoda, Laura Leal e Lívia Menezes Pagotto

Diagramação: Alastra, Comunica.

Impressão: Forma Certa

ISSN: 2674-8061

DOI: doi.org/10.33816/gife.20200202a6

(C) 2020 GIFE - Grupo de Institutos Fundações e Empresas

\section{(C) (i) ()}

Este material é disponibilizado sob a licenca Creative Commons Atribuição Não Comercial 4.0 Internacional. http://creativecommons.org/licenses/by-nc/4.0

As opiniões e análises expressas nesta publicação não necessariamente refletem as do GIFE.

\author{
Apoio institucional \\ Alana \\ Ford Foundation \\ Fundação Bradesco \\ Fundação Lemann \\ Fundação Tide Setubal \\ Instituto Unibanco \\ Laudes Foundation
}

